\title{
KNOWLEDGE ABOUT HIV/AIDS AMONG DRIVERS IN BIRGUNJ BUS PARK: A DESCRIPTIVE ANALYSIS
}

\author{
Shambhu Prasad Patel \\ Department of Statistics, TU, Thakur Ram Multiple Campus, Birganj, Nepal \\ E-mail: sagar_peacezone2oo8@yahoo.com
}

\begin{abstract}
One of the growing epidemics in the world today is HIV/AIDS. In the cities with high mobility, bus drivers are considered as the risk group for HIV/AIDS. Most of these younger people do not have access to information, condoms, supportive services which enable them to have safer sex. A descriptive cross sectional study was done to access knowledge about HIV/AIDS among drivers of Birgunj Bus Park. The analysis of the data revealed that majority of the respondents were between ages 20-24 years; have heard from media (radio, Television and newspapers); unsafe sex is the means of transmission and using condom during sexual intercourse can prevent HIV/AIDS. The present study strongly recommends that there is immediate need of program to create awareness among drivers including co-workers, vulnerable youths and other high risk groups such as migrant populations.
\end{abstract}

\section{Keywords}

Analysis; Drivers; HIV/AIDS; Public health; Statistics

\section{Introduction}

HIV/AIDS is the biggest public health challenges in the world today. Even though the prevalence of HIV infection is showing declining trend in present times, globally, estimated 33.2 million individuals are infected with HIVassofarand total number of 2.1 million deaths are reported since the identification of first case of HIV/AIDS in US in the year 1981. In
Asia, an estimated 4 million people are living with HIV/AIDS in 2007 (UNAIDS, 2004). The HIV/AIDS epidemic poses a serious threat to the population of Nepal, especially the lives of children and young people. Current data indicates that HIV prevalence is around 0.5 percent in the adult population (15-49 years) (NCASC/FHI, 2003, 2005). Nepal is experiencing transition of HIV epidemic. 
Various predisposing factors are prevalent for the rapid spread of HIV in Nepal. Underlying factors associated with HIV/AIDS in Nepal are Poverty, ignorance, migration, political turmoil and gender inequality (UNICEF, 2006). HIV thrives on mobile population. Birgunj is head quarter of Parsa district and fast growing city of Nepal. It is center for the migrant of young population because this district is linked by Tribhuvan highway which has relatively extensive road networks. A national situation analysis identified female sex workers, mobile populations, men who have sex with men, injecting drug users, young people, and infected children as the groups most vulnerable to HIV in Nepal to day(NCASC,2003,2005;NDHS,2011). To date most attention has been paid to high -risk groups such as female sex workers and their clients, injecting drug users, seasonal labor migrants, and truckers. Drivers are one of the highly vulnerable groups to HIV because they are highly mobile and unaware (Orisatoki, 2010). Hence the present study was conducted to assess the knowledge regarding HIV/AIDS among the drivers of Birgunj Bus Park and expected that the findings of the study will be beneficial to design appropriate preventive strategies.

\section{Methodology}

A descriptive cross sectional study was carried out to assess the knowledge about HIV/ AIDS among bus drivers of Birgunj bus Park. 50 drivers were randomly selected for the study. Verbal consent was taken from all the participants prior of collecting the information and privacy were maintained during data collection. Data was collected through close ended questionnaire and interview method. The data was analyzed with the help of simple descriptive statistics.

\section{Results}

Application of descriptive statistics on data gave the following results.
Table 1: Demographic characteristic of the respondents $(\mathbf{n}=\mathbf{5 0})$

\begin{tabular}{|c|c|c|}
\hline Sex & Frequency & Percentage \\
\hline Male & 50 & 100 \\
\hline Female & 0 & o \\
\hline \multicolumn{3}{|l|}{ Age } \\
\hline 15-19 years & 5 & 10 \\
\hline 20-24 years & 12 & 24 \\
\hline $25-29$ years & 15 & 30 \\
\hline$>30$ years & 18 & 36 \\
\hline \multicolumn{3}{|l|}{ Marital Status } \\
\hline Married & 40 & 80 \\
\hline Unmarried & 10 & 20 \\
\hline \multicolumn{3}{|l|}{ Ethnicity } \\
\hline Hindu & 30 & 60 \\
\hline Islam & 15 & 30 \\
\hline Sikh & 5 & 10 \\
\hline \multicolumn{3}{|c|}{ Educational Status } \\
\hline $\begin{array}{l}\text { Primary level \& } \\
\text { lower secondary }\end{array}$ & 30 & 60 \\
\hline Secondary level & 18 & 36 \\
\hline $\begin{array}{l}\text { Higher secondary } \\
\text { and above }\end{array}$ & 2 & 4 \\
\hline
\end{tabular}

Table 2 : Knowledge regarding transmission of HIV/AIDS $(n=50)$

\begin{tabular}{|l|l|r|}
\hline \multicolumn{1}{|c|}{$\begin{array}{c}\text { Mode of } \\
\text { transmission }\end{array}$} & Knowledge & $\begin{array}{c}\text { Number } \\
(\%)\end{array}$ \\
\hline \multirow{2}{*}{ Unsafe sex } & Yes & $46(92)$ \\
\cline { 2 - 3 } & No & $4(8)$ \\
\hline \multirow{2}{*}{$\begin{array}{l}\text { Pregnant } \\
\text { mother to fetus }\end{array}$} & Yes & $45(90)$ \\
\cline { 2 - 3 } $\begin{array}{l}\text { Sharing of } \\
\text { contaminated } \\
\text { needle, blade }\end{array}$ & Yes & $5(10)$ \\
\cline { 2 - 3 } $\begin{array}{l}\text { Sharing of } \\
\text { cloths, towels }\end{array}$ & Yes & $48(96)$ \\
\cline { 2 - 3 } & No & $2(4)$ \\
\hline Kissing & Yes & $40(80)$ \\
\cline { 2 - 3 } & No & $5(10)$ \\
\hline
\end{tabular}




\section{Table 3: Knowledge about prevention of hiv infection $(n=50)$}

\begin{tabular}{|l|c|c|}
\hline Ways of prevention & No. & \% \\
\hline Use of condom & 30 & 60 \\
\hline New needles for IVDUS & 5 & 10 \\
\hline $\begin{array}{l}\text { Blood from accredited } \\
\text { blood bank }\end{array}$ & 3 & 6 \\
\hline Safe Sex & 7 & 14 \\
\hline PPTCT & 2 & 4 \\
\hline $\begin{array}{l}\text { Not to touch/ talk } \\
\text { infected person }\end{array}$ & 1 & $\mathbf{2}$ \\
\hline Avoid kissing & $\mathbf{1}$ & $\mathbf{2}$ \\
\hline Contraceptive pills & $\mathbf{5 0}$ & $\mathbf{1 0 0}$ \\
\hline Total & & \\
\hline
\end{tabular}

Among the participants all $100 \%(n=50)$ of the participants were male. Majority of the respondents $36 \%(n=18)$ were above 30 years old. $62 \% \quad(n=31)$ of the respondents had secondary level of schooling. As per ethnicity $60 \% \quad(n=30)$ of respondents were Hindu followed by Islam and Buddhist as shown in table 1 . Regarding transmission of HIV/AIDS, $92 \%(n=46)$ of the respondents mentioned that unsafe sex is the means of transmission, $96 \%(n=48)$ of the respondents mentioned that sharing of the needles, and 90\% $(n=45)$ of the respondents mentioned that HIV transmits from pregnant mother to fetus. However, still $20 \%(\mathrm{n}=10)$ believe that sharing clothes and $10 \%(\mathrm{n}=5)$ believe that kissing can transmit HIV/AIDS as shown in table 2. As per prevention measures $60 \%(n=30)$ have the knowledge that using condom during sexual intercourse can prevent HIV/AIDS.

\section{Discussion}

The present was undertaken in December 2012, to assess the level of knowledge among drivers from Birgunj Bus Park. Total number of 50 drivers selected randomly was interviewed and desired data were collected through structured questionnaire. The descriptive analysis of present study of 50 bus drivers from Birgunj revealed that all the respondents have heard about HIV/AIDS, however knowledge about modes of transmission and methods of prevention are still inadequate. As per our study $100 \%(n=50)$ respondents have heard about HIV/AIDS. Regarding transmission of HIV/AIDS, 92\% $(n=46)$ of the respondents mentioned that unsafe sex is the means of transmission, $98 \%(n=48)$ of the respondents mentioned that sharing of the needles, $92 \%$ and $90 \%(\mathrm{n}=45)$ of the respondents mentioned that HIV transmits from pregnant mother to fetus. It infers that most respondents knew that HIV/AIDS can be transmitted through sexual intercourse, sharing of needles, blood transfusion and from mother to fetus. Our study shows close agreement with the finding of Chaturvedi et al. (2006) who revealed that 94.6\% of the drivers were aware that HIV can be transmitted by heterosexual route, $86.2 \%$ were about transmission by contaminated needle and $84.4 \%$ were aware about transmission by blood transfusion. Likewise, the study done in West Indies amongst taxi drivers revealed that $76.7 \%$ of them were aware of the various modes of transmission and $73.3 \%$ were knowledgeable about risk of contracting the infection (Chaudhary et al.2005; Orisetoki, 2010). Several misconceptions about transmission were recorded in our study. Misconceptions as regards to transmission of HIV/AIDS by sharing of clothes, kissing were present among bus drivers. Our study revealed that still $20 \%(n=10)$ believe that sharing clothes and \%10 $(n=5)$ believe that kissing can transmit HIV/AIDS. Chaudhry et al.(2005) also reported the misconception among the drivers. Misconceptions as regards to transmission of HIV/AIDS by mosquito bite and using public toilet were present among drivers. The prevalence of misconceptions among these drivers is probably due to their low educational status. These misconceptions can lead to increased discrimination against patients of HIV/AIDS. These misconceptions need to be addressed through AIDS intervention programs as 
it has implications for wrong attitudes towards people living with AIDS. Prevention programs for this group of workers should focus on eliminating these misconceptions and include specific interventions to effect a change in sexual behavior in order to reduce the risk of transmission of the disease in the community. As per prevention measures $60 \%$ $(\mathrm{n}=30$ have the knowledge that using condom during sexual intercourse can prevent HIV/ AIDS. The findings of the study done in Tanzania(Mugoyelaand V,Charles V,2009) show close agreement with our study where $60 \%(n=30)$ of the drivers believe that using condom can prevent HIV/AIDS.

\section{Conclusion}

Beingthesexuallyactiveagegroupand frequent mobility, drivers are epidemiologically important risk group as far as transmission of HIV infection is concerned. Present study undertaken to study to assess the level of knowledge about HIV/AIDS among drivers of Birgunj bus Park reveals that majority of drivers have heard of HIV/AIDS and are also aware about use of condoms as one of the important method of prevention of infection. Unsafe sexual relationship is identified as the most important route of transmission of HIV/AIDS. The study also reveals there are still misconceptions regarding modes of transmission and ways of prevention of HIV infection. Knowledge on the transmission of HIV/AIDS and means of prevention needs to be articulated to them. To overcome these lacunae there is an immediate need of program to create awareness among drivers and co-workers, vulnerable youths and other high risk groups of people including migrant populations. There is a scope to promote intensified studies especially for drivers and those with low level of education and low socioeconomic profile.

\section{Reference}

BAlla, S., Cahandwani, H., Singh, D. \& Som Sundharam, C. (2005). Knowledge about HIV/AIDS among senior secondary school students in
Jamnagar, Gujarat. HPPI, 28: 178-188.

Chaturvedi S, Singh Z, Banerjee A, Khera A, Joshi R.K. , Drubajyoti D (2006). Sexual behaviour among long distance truck drivers. Indian Journal of Community Medicine. 3:53-56.

Chaudhary MA, Naeem M, Iqbal R, Sabbir I (2005). Level of awareness about HIV/AIDS among drivers and their attitude towards person with AIDS. GJMS. 3: 19-23.

Mugoyelaand V, Charles V (2009). Knowledge of HIV/AIDS preventive measures use by city commuter bus drivers conductors in Dar Es Salaam, Tanzania. East Afr. Public Health.6:73-6.

NCASC (2005). Stigma and discrimination in health settings in Nepal: case studies among technical health workers, non-technical health workers and people living with HIV/AIDS, National Centre for AIDS and STD Control (NCASC), Kathmandu.

NCASC/FHI (2003). National estimates of adult HIV infection s: Nepal, 2003. National Centre for AIDS and STD Control (NCASC), Family Health International (FHIo), Kathmandu.

NDHS (2011).Annual report, Department of Health, Services, Ministry of Health \& Population, Kathmandu.

Orisatoki, RO, Oguntibeju (2010). HIV-related knowledge and condom use by taxi drivers in southern St. Lucia, West Indies. Scientific Research \& Essay, 5: 19-23.

Sudha RT, Vijay DT, Laxmi V (2005). Awareness, attitude and beliefs of the general public towards HIV/AIDS in Hyderabad, a capital city from South India. Indian Journal of Community Medicine. 59: 307-316.

UNAIDS (2004). Report on the global AIDS Epidemic, UNAIDS, Geneva.

UNAIDS/NCASC (2004). The HIV/AIDS/STD situation and national response in Nepal: Country report, UNAIDS, National Centre for AIDS and STD Control (NCASC), Kathmandu.

UNICEF (2006). Situation of children and women in Nepal. UNICEF Nepal, Kathmandu. 